\title{
Seroprevalence of Surrogate Markers for Hepatitis B, Hepatitis C and HIV in Healthy Blood Donors at Shaikh Zayed Medical Complex, Lahore
}

\author{
SHAH S.A.R. ${ }^{1}$, EHSAN A. ${ }^{2}$ \\ Address for Correspondence: Dr. Shahida Amjed Riaz Shah, Department of Haematology, Sheikh Zayed Postgraduate \\ Medical Institute, Lahore
}

Introduction: This project was aimed to determine the seropositivity status for Hepatitis B surface antigen (HBsAg), anti Hepatitis C (HCV) antibodies and antibodies to Human Immune Deficiency Virus (HIV) I and II in healthy blood donors donating blood at Shaikh Zayed Hospital Lahore.

Material and Methods: The relevant data was collected during a period of 28 months from $1^{\text {st }}$ January 2006 till $31^{\text {st }}$ March 2008. It was a cross sectional study which entailed screening of 60719 healthy donors. The donors were aged between 16 years to 45 years. There were $93.43 \%$ males and $6.57 \%$ females.

Results: The seroprevalence of Anti HCV antibodies was 3.870\%; for HBsAg it was 1.407\%; for HIV antibodies it was $0.00658 \%$. Our study demonstrated a higher seropositivity for HIV in healthy donor population than all of the previous reports except one with which it matched precisely. HBsAg showed a definite downwards inclination when compared with similar previous studies carried out in the last 7 years. Seroprevalence of anti HCV antibody was found to be similar when compared with previous studies and demonstrated a higher trend in large cities with a multiethnic population.

Key Words: MeSH: Blood donors, seroprevalence, HbsAg, antiHCV, HIV.

\section{Introduction}

Viral hepatitis by HBV and HCV viruses is a world wide public health problem, representing a significant cause of morbidity and mortality in developing countries. An estimated $2.2 \%$ of the world population is infected by HCV infection. Most of the 140 million people positive for anti HCV antibodies are chronically infected, making HCV one of the most common chronic blood borne viral infections in the world. It is estimated that 350 million people worldwide are chronic HBV carriers representing approximately $7 \%$ of the total population ${ }^{2}$. Chronic HBV infection is endemic in Southeast Asia where $10 \%$ population may be infected ${ }^{3}$.

$\mathrm{HBV}$ and $\mathrm{HCV}$ virus can cause a spectrum of clinical conditions ranging from symptom free carrier state to chronic hepatitis, liver cirrhosis and hepatocellular carcinomas ${ }^{4}$. In highly industrialized countries, illicit use of drug injections account for most HBV and HCV infections ${ }^{5}$, whereas in developing countries, the majority of infections are attributable to parenteral exposure in health care settings, particularly unsafe injections ${ }^{6}$. Sexual transmission of HCV occurs but is inefficient and probably accounts for a small proportion of all infections ${ }^{5}$. Blood transfusion also accounts for a substantial proportion of cases if transfused without screening for surrogate markers and antibodies to HBV, HCV and HIV. In Pakistan prior to introduction of donor screening for hepatitis, transfusion of blood or plasma derived products was associated with significant risk of acquisition of HBV and $\mathrm{HCV}^{8}$. By 2003 contaminated blood and blood products accounted for $7 \%$ of the total transmission of HIV/AIDS in Pakistan ${ }^{7}$.

This study was conducted to evaluate the seropositivity of healthy blood donors for HIV, HBsAg \& anti HCV antibodies who donated blood at Shaikh Zayed Hospital, Lahore.
The information gained by such studies provides direction for setting new goals in developing preventive strategies in Transfusion Transmitted Infections. They also provide a means for reviewing outcome of the preventive measures which are already in place.

\section{Materials and Methods}

This was a cross sectional study on 60719 healthy blood donors bled at Sheikh Zayed Hospital, Lahore during a period of 28 months from $1^{\text {st }}$ January 2006 till $31^{\text {st }}$ March 2008. Five $\mathrm{ml}$ of blood was collected from the donor, $2 \mathrm{ml}$ blood was added to EDTA containing test tube for determination of blood group and haemoglobin estimation. Three $\mathrm{ml}$ of blood was allowed to clot; blood serum was used for cross matching, screening for Hepatitis B, Hepatitis C and HIV. Detection of HBsAg was done using ELISA technique (Monolisa ${ }^{\circledR}$ HBsAg Kit) (Sensitivity 100\%; specificity 99.94\%). Anti Hepatitis C antibodies were detected by a rapid binding test (Instatest HCV). All anti HCV antibody positive samples were reconfirmed by ELISA technique (bioelisa HCV 4.0) (Sensitivity 100\%; specificity 99.8\%). Anti HIV I and/ or Anti HIV II antibodies were detected using ELISA technique (Vironostica ${ }^{\circledR}$ HIV Uniform II Ag/Ab kit) Sensitivity 100\%; specificity 99.9\%. The tests were done precisely according to the instructions of the manufacturer.

\section{Results}

A total of 60719 healthy donors were screened during a period of 28 months from $1^{\text {st }}$ January 2006 till $31^{\text {st }}$ March 2008 at Shaikh Zayed Hospital, Lahore. This donor cohort represented the population belonging predominantly to Lahore and its suburbs. The majority of the donors were 
directed donors (42004) i.e. 69.17\% with a smaller proportion consisting of replacement donors (18033) i.e. 29.7\%, either close relatives or friends of the recipient. Only $1.12 \%$ donors (682) were nonrenumerated voluntary donors belonging to the medical staff and students associated with Shaikh Zayed Medical Complex, Lahore. The donor cohort was between 16 to 45 years of age, 56730 (93.43\%) were males and 3989 (6.57\%) were females. The female donor population was found to belong predominantly to the voluntary non numerated donors which constituted $41.7 \%$ (76 in number) of the voluntary donors, however it constituted only $6.44 \%$ of the rest of the donor cohort. The HBsAg positivity was present in 854 blood donors (1.406\%); Anti HCV antibodies were seen in 2350 blood donors (3.870\%); and HIV positivity was present in 4 donors (0.00658\%).

\section{Discussion}

The donor trends suggest predominance of directed donations, followed by replacement donations where the blood group was not available within family and friends of the patient. This is a direct consequence of lack of availability of donor data registration at district, provincial or national level. The significantly high female participation in the voluntary donor cohort points towards an untapped blood resource which is much less likely to be used if the donations continue to be directed or replaced ones.

Hepatitis B and C have emerged as major health hazards in Pakistan. Unscreened blood products have a significant role in spread of these infections. Screening of blood donors provides substantial data regarding the serostatus of healthy young male population of the local area.

Seroprevalence of anti HCV antibodies in healthy blood donors is different in different parts of the country. The results of this study showed a seroprevalence of $3.87 \%$ in the target population. The results were compared with other similar studies from Pakistan with a larger than 10,000 sample size to see the trend and geographical distribution of infectivity in Table 2 and Figure 2. Studies from smaller cities were also assessed to review the reported blood donor data of various cities of Pakistan in the last 6 years. However the sample size of these studies was relatively small so they could not be compared to the results of the present study. Studies from Sialkot reported $3.26 \%{ }^{18}$, from Peshawar reported $1.34 \%$ and $2.6 \%{ }^{15}$, from Quetta $1.87 \%^{20}$, from Multan $0.27 \%{ }^{19}$ seropositivity of anti $\mathrm{HCV}$ antibodies. It was noticed that Anti
Table 1: Comparison of HBsAg seroprevalence in blood donors in various parts of the country.

\begin{tabular}{|l|l|l|l|}
\hline \multicolumn{1}{|c|}{ City } & \multicolumn{1}{c|}{ Author } & Year & $\begin{array}{c}\text { HBsAg sero- } \\
\text { prevalence \% age }\end{array}$ \\
\hline Lahore ${ }^{\text {(Present Study) }}$ & Shah SAR & 2008 & 1.406 \\
\hline Karachi (13) & SA Mujeeb & 2007 & 3.3 \\
\hline Bahawalpur (11) & MA Khan et al & 2006 & 2.69 \\
\hline Lahore (10) & Sirhindi et al & 2005 & 3.36 \\
\hline Islamabad (9) & Khokhar N et al & 2004 & 2.56 \\
\hline Rawalpindi (12) & Khattak MF & 2002 & 3.3 \\
\hline Punjab (8) & Rahman M et al & 2002 & 2.259 \\
\hline
\end{tabular}

Table 2: Comparison of Anti HCV seroprevalence in blood donors in various parts of the country.

\begin{tabular}{|l|l|l|c|}
\hline \multicolumn{1}{|c|}{ City } & \multicolumn{1}{|c|}{ Author } & Year & $\begin{array}{c}\text { AntiHCV sero- } \\
\text { prevalence \% age }\end{array}$ \\
\hline Lahore $^{\text {(Present Study) }}$ & Shah SAR & 2008 & 3.87 \\
\hline Karachi (13) & SA Mujeeb & 2007 & 3.3 \\
\hline Bahawalpur (11) & Khan MA & 2006 & 2.52 \\
\hline Lahore (10) & Sirhindi & 2005 & 4.16 \\
\hline Islamabad (9) & Khokhar N & 2004 & 5.31 \\
\hline Rawalpindi (12) & Khattak MF & 2002 & 4.0 \\
\hline
\end{tabular}

Table 3: Comparison of Anti HIV antibodies seroprevalence in blood donors in various parts of the country.

\begin{tabular}{|l|l|l|c|}
\hline \multicolumn{1}{|c|}{ City } & \multicolumn{1}{|c|}{ Author } & Year & $\begin{array}{c}\text { Anti HIV antibodies } \\
\text { seroprevalence \% age }\end{array}$ \\
\hline Lahore $^{\text {(present Study) }}$ & Shah SAR & 2008 & 0.00658 \\
\hline Bahawalpur (11) & Khan MA & 2006 & 0 \\
\hline Lahore (10) & Sirhindi & 2005 & 0 \\
\hline Punjab (8) & Rahman M & 2002 & 0.001 \\
\hline Rawalpindi (12) & Khattak MF & 2002 & 0.007 \\
\hline
\end{tabular}

HCV infectivity has remained at a somewhat similar level during the last 6 years and showed a geographical distribution with a higher percentage in larger well populated cities of Lahore, Islamabad, Rawalpindi and Karachi.

Seroprevalence of HBV, on the other hand, showed a similar level in healthy blood donors tested in different parts of the country. The results of this study i.e. $1.406 \%$ were compared with other similar studies from Pakistan with a large sample size in Table 1, Figure 1. It was found to be somewhat lower than the other large pool studies carried out previously. It was reduced by about $0.9 \%$ when compared with a similar study reported from the same hospital in $2005^{10}$. Other studies from smaller cities with smaller sam- 


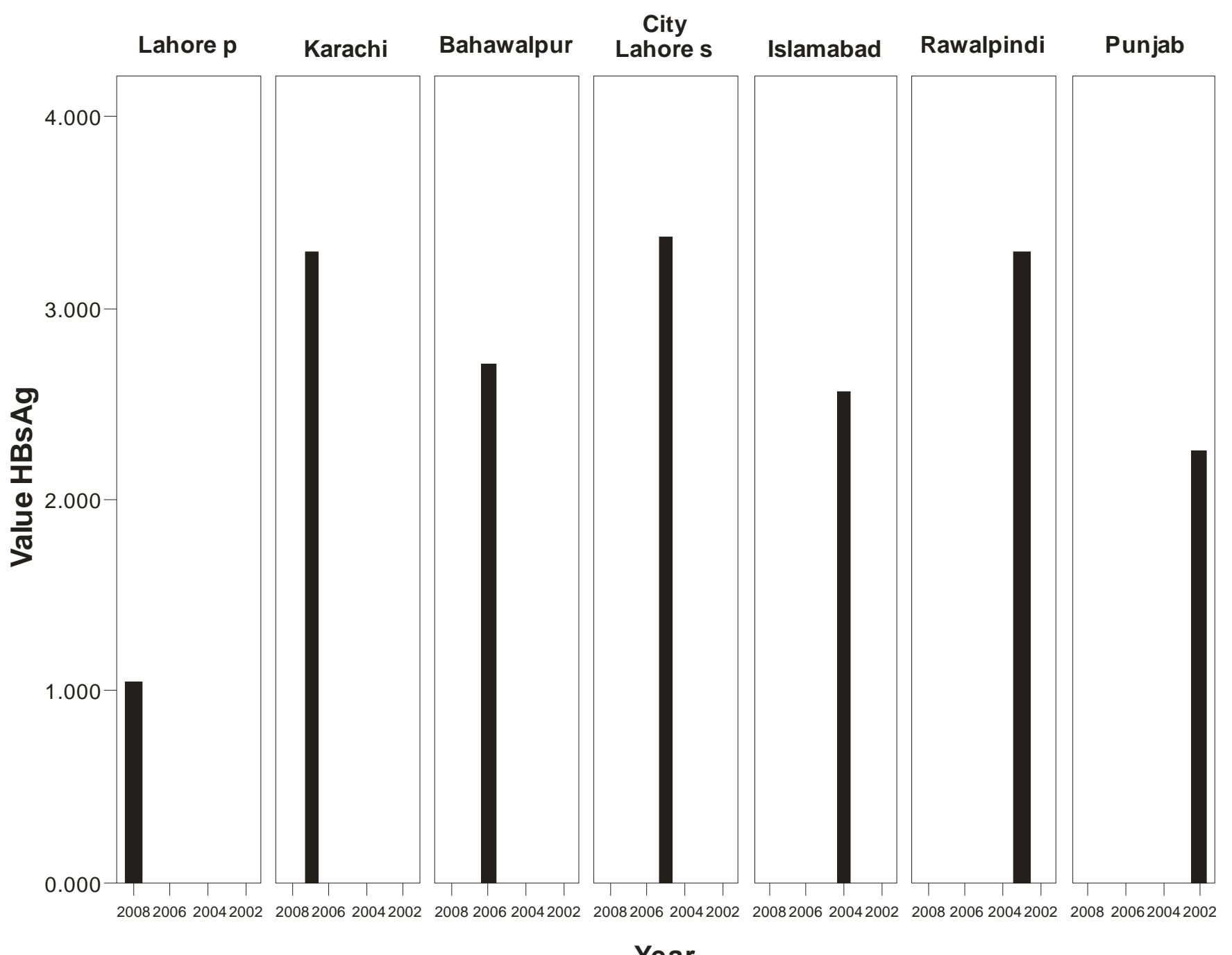

Key: Lahore p stands for present study

Year

Lahore s stands for study by Sirhindi et al.

Figure 1: Comparison of reported seroprevalence of HBsAg from different cities along with the year of publication of the study.

ple size reported $1.75 \%$ and $1.4 \%$ HBsAg seropositivity from Peshawar ${ }^{15}, 3.37$ from Multan ${ }^{20}$. The present study indicated a lower seropositivity for HBsAg than the previously reported statistics from similar large pool studies. The most likely cause could be the nationwide free immunization drive for Hepatitis B which has similarly reduced the infectivity of Hepatitis B in other Southeast Asian countries. $^{23,24}$

HIV antibody seroprevalence has been reported to be very low in healthy blood donor population of Pakistan. The present study reported a seroprevalence of $0.00658 \%$ which is identical to that reported from Rawalpindi i.e. $0.007 \%{ }^{12}$. Earlier from Lahore Sirhindi and from Bahawalpur MA Khan reported no HIV positive cases in a large pool of donors. ${ }^{10,11}$ Seroprevalence of HIV was reported as $0.001 \%{ }^{8}$ from Punjab (Table 3, Figure 3). Other reports were nil seroprevalence from Rawalpindi, ${ }^{11,22}$ Quetta ${ }^{19}$ and Peshawar $^{10}$ in blood donors. Our study demonstrated a seropositivity of $0.00658 \%$ in healthy donor population which is somewhat higher than most of the reports from Pakistan till now.

\section{Conclusion}

The present study presented data from a large donor pool size and may be considered representative of the young healthy male population from Lahore and its suburbs. It demonstrated a lower seropositivity for HBsAg than the previously reported statistics from similar large pool studies. The most likely cause could be the nationwide free immunization drive for Hepatitis B. It was noticed that the reported Anti HCV seroprevalence level remained at a somewhat similar level during the last 6 years and showed a geogra- 


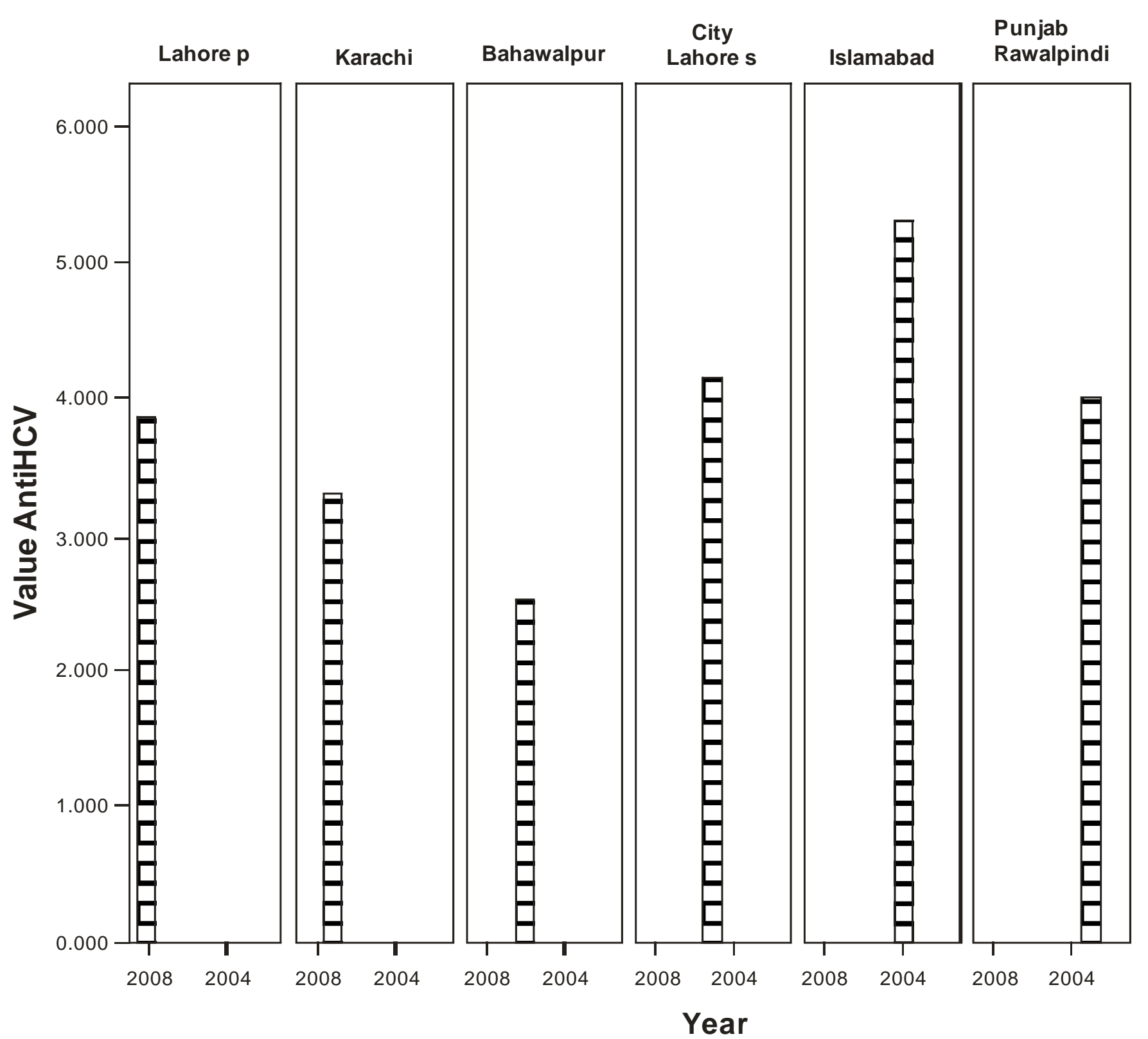

Key: Lahore p stands for present study Lahore s stands for study by Sirhindi et al.

Figure 2: Comparison of reported seroprevalence of Anti HCV from different cities along with the year of publication of the study.

phical distribution with a higher percentage in larger well populated cities. Seropositivity for HIV in this study was higher in healthy donor population than most of the large pool donor screening studies reported in local literature. This rise of HIV reactive cases in supposedly healthy blood donors who are being tested for directed blood donations is suggestive not only of a higher endemic status, but also of an increasing segment of unaware population at risk of spreading the disease.

\section{References}

1. The Global Burden of Hepatitis C Working Group, 2004. Global burden of disease (GBD) for hepatitis C. $J$ Clin Pharmacol 44: 20-29.

2. kao JH, Chen PJ, Lai MY, Chen DS 2002. Occult hepatitis B virus infection and clinical outcomes of patients with chronic hepatitis C. J Clin Microbiol 40: 4068-4071. 


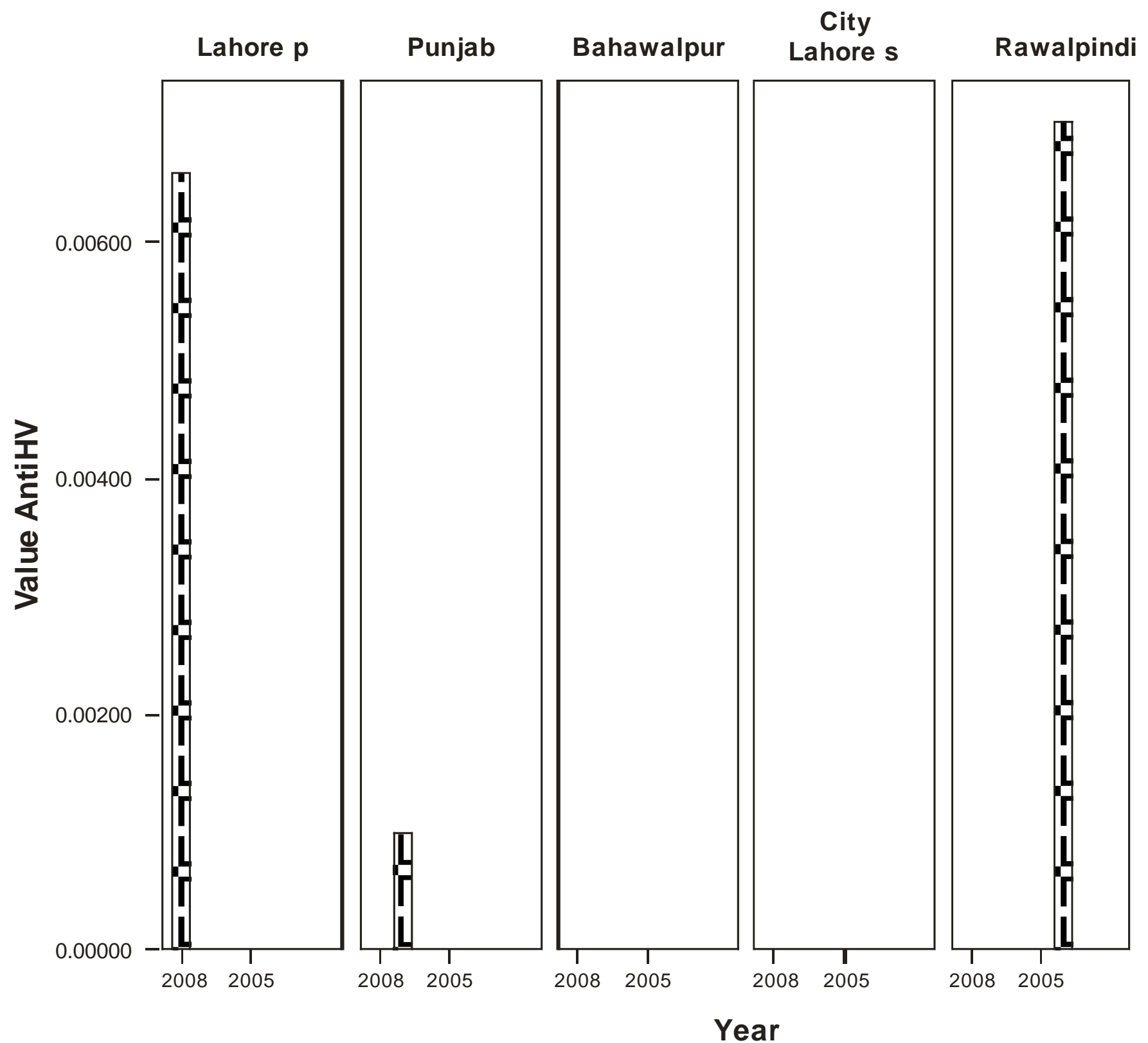

Key: Lahore p stands for present study Lahore s stands for study by Sirhindi et al.

Figure 3: Comparison of reported seroprevalence of HIV from different cities along with the year of publication of the study.

3. Purow D, Jacobson IM 2003. Slowing the progression of chronic hepatitis B: early antiviral therapy can help minimize complications. Postgrad Med 114: 65-76.

4. Chattopadhayay S, Rao S, Das BC, Singh NP, kar P2005. Prevalence of transfusion transmitted viral infection in patients on maintenance hemodialysis from New Delhi, India. Haemodial Int 9: 362-366.

5. Mast EE, Alter MJ, Margolis HS, 1999. Strategies to prevent and control hepatitis B and C virus infections: a global perspective. Vaccine 17: 1730-1733
6. Hauri AM, Armstrong GL, Hutin YJ, 2004. The global burden of disease attributable to contaminated injections given in health care settings. Int J STD AIDS 15: 7-16.

7. UNDP (2006) You and aids; the HIV/AIDS portal of Asia and Pacific, Pakistan at a glance (www.youandaids.org).

8. Rahman M, Akhtar GA, Lodhi Y. Transfusion transmitted HIV\& HBV infections in Punjab, Pakistan. 2002; 18 (1); 18-25. 
9. Khokhar N, Gill ML, Malik GJ. Seroprevalence of HCV in healthy blood donors is different in different parts of the country. J Coll Physicians Surg Pak. 2004; 14 (9): 534-6.

10. Sirhindi GA, Khan AA, Alam SS, Ghori MA, Rehman R, Soomro NA, et al. Frequency of Hepatitis B, C and Human Immunodeficiency virus in blood donors at Shaikh Zayed Hospital, Lahore. Proceeding Shaikh Zayed Postgrad Med Inst Jun 2005; 19 (1): 33-6.

11. Khan MA, Chaudhary GM, Fayyaz M, Qazi MA, Ahmed G. Hepatitis B, C \& HIV; seroprevalence of infection in blood donors. Professional Med J Dec 2006; 13 (4): 632-36.

12. Khattak M F, Salamat N, Bhatti F A, Qureshi TZ. Seroprevalence of hepatitis B, C and HIV in blood donors in northern Pakistan. J Pak Med Assoc Sep 2002; 52 (9): 398-402.

13. Mujeeb SA, Pearce MS. Seroprevalence and determinants of risk of hepatitis $B$ and $C$ viral infections in blood donors: a cross sectional analytical study. J Infect Developing Countries 2007; 1 (1): 17-24.

14. Ahmad J, Taj AS, Rahim A, Shah A, Rehman M. Frequency of Hepatitis B and hepatitis V in healthy blood donors of NWFP: a single centre experience. J Postgrad Med Inst 2004; 18 (3): 343-52.

15. Zaidi A, Tariq WZ, Haider KA, Ali L, Sattar A et al. Seroprevalence of hepatitis B, C, HIV in healthy blood donors in Northwest of Pakistan. Pak J Pathol 2004; 15 (1): 11-16.

16. Chaudhry IA, Samiullah, Khan SS, Masood R, Sardar MA, Malhi AA. Seroprevalence of hepatitis B and C among the healthy blood donors at Fauji foundation
Hospital, Rawalpindi. Pak J Med Sci 2007; 23 (1): 6467.

17. Ahmad S, Gull J, Bano KA, Aftab M, Khokhar MS. Prevalence of anti hepatitis $\mathrm{C}$ antibodies in healthy blood donors at services Hospital Lahore. Pakistan Postgrad Med J 2002; 13 (1): 18-20.

18. Alam M, Ahmad D. Prevalence of antibodies to hepatitis c virus in blood donors in sialkot. J Coll physicians Surg Pak 2001; 11 (12); 783.

19. Mahmood MA, Khawar S, Anjum AH, Ahmad SM, Rafiq S, Nazar I et al. Prevalence of hepatitis B,C and HIV infection in blood donors of Multan region. Ann king Edward med Coll 2004; 10 (4): 459-61.

20. Ali N, Nadeem M, Qamar A, qureishi AH, Ejaz A. Frequency of Hepatitis $\mathrm{C}$ virus antibodies in blood donors in Combined Military Hospital, Quetta. Pak J med Sci 2003; 19 (1): 41-4.

21. Khattak MF, Salamat N, Bhatti FA, Ahmad A, Tariq WUZ. Epidemiology of Hepatitis $C$ virus infection in bloods donors in Northern Pakistan. J Coll physicians Surg Pak 2002; 52 (9); 398-402.

22. Mumtaz S, Rahman M, Muzaffar M, Hassan M, Iqbal W. Frequency of seropositive blood donors for hepatitis B, C and HIV in railway hospital Rawalpindi. 2002; Pak J Med Res; 41 (2): 51-53.

23. Ruff TA, Gertig DM, Otto BF et al. Lombok hepatitis B model immunization project: toward universal infant hepatitis B immunization in Indonesia. J Infect Dis 1995; 171 (2): 290-96.

24. Huang K, Lin S. Nationwide vaccination: a success story in Taiwan. Vaccine 2000; 18 (S1): S35-8 